\title{
Investigando a recepção em um projeto de teatro na comunidade
}

Beatriz Angela Vieira Cabral*

Dan Olsen**

\section{Sumário}

Esta pesquisa examinou distintas formas de recepção estética a um projeto de teatro em comunidade - envolveu atores do Curso de Licenciatura em Teatro da UDESC, atores da comunidade sem experiência anterior na área, e espectadores. Uma investigação quantitativa foi conduzida por Dan Olsen (Universidade de Slagelvelsem, Dinamarca) e subsidiou a subseqüente análise qualitativa por Beatriz Cabral (UDESC/UFSC).

O objetivo foi obter, com a colaboração de Dan Olsen, dados específicos sobre o impacto da experiência nos participantes, como ponto de partida para ampliar e aperfeiçoar a compreensão dos mesmos a respeito da estética teatral sendo investigada, e em decorrência, sua recepção ao projeto em curso.

Os procedimentos incluíram a aplicação de um questionário centrado nos objetivos estéticos e pedagógicos do projeto. O cruzamento dos dados e suas variáveis salientaram pontos de vista e interesses, similares e distintos, por parte dos três grupos que interagiram neste espetáculo.

\section{Introdução}

"Teatro em Trânsito - formas interativas de teatro em comunidade" é um projeto de pesquisa que investiga uma estética teatral centrada na realização de cenas distintas e simultâneas, realizadas em lugares representativas da memória histórica de uma comunidade, e estruturadas a partir do cruzamento entre fatos e histórias populares vinculados a estes lugares. As cenas se repetem tantas vezes quantas forem o seu número, e a caminhada dos espectadores de uma cena à outra outorga ao evento um sentido de cerimô-

* Beatriz Angela Vieira Cabral, professora do Programa de Pós-Graduação em Teatro UDESC.

** Dan Olsen, professor Universidade de Slagelvelsem - Dinamarca 
nia e confraternização.

Esta forma teatral se baseia na interação entre alunos e professores de teatro com os moradores da comunidade na qual se realiza o trânsito, entre os quais se encontram pessoas de diversos extratos sociais e diferentes idades. A interação acontece no interior de cada cena, entre os elencos das diversas cenas, no contato com o público, com as pessoas entrevistadas a respeito das histórias locais, e com todos aqueles que cederam espaços físico e materiais de apoio. As formas interativas que promovem esta interação constituíram a fase inicial desta pesquisa (2001-2002) e se referem às estratégias e convenções teatrais utilizadas.

Trata-se de um projeto de montagem intercultural, onde o elenco de cada cena é composto pelos "daqui" e os "de fora", os quais associam histórias de vida e memórias à estrutura dramática criada pelo grupo de pesquisa. As cenas, com uma duração máxima de 10 minutos cada uma, resumem momentos da história ou histórias mitológicas coletadas através de entrevistas com idosos da comunidade. Neste sentido, além do resgate histórico, se está fazendo história.

Foram realizados quatro trânsitos, entre 2001 e 2004, um por ano. A investigação, de caráter processual, pode ser caracterizada enquanto prática como pesquisa, uma vez que a experiência acumulada inter-relaciona pesquisa e extensão e se reflete nas disciplinas ofertadas na graduação e mestrado. O foco atual da investigação está centrado nas questões de impacto e risco e o planejamento e análise metodológica inclui estudos sobre inclusão e democratização das diferenças. A avaliação contínua está amparada pelas teorias de Pierre Bourdieu (no que se refere à avaliação diagnóstica) e Henri Giroux (no que se refere ao planejamento de situações que envolvam travessias teóricas e práticas).

Este artigo focaliza a experiência realizada em 2003 no município de Bombinhas/SC, a qual contou com a participação de Dan Olsen na esfera da observação, documentação e parceria na análise de dados. A análise de impacto e risco, decorre da aplicação de um questionário, usado como suporte para a realização de entrevistas após o espetáculo.

\section{Coleta de Dados}

O questionário reúne informações sobre a recepção do espetáculo por três grupos distintos de participantes: atores com experiência anterior (alunos e professores de teatro), atores sem experiência anterior (participantes da comunidade) e espectadores. Suas questões focalizam os objetivos do 
projeto teatral. O questionário e entrevista permitem assim examinar a eficácia da forma com que estes objetivos foram realizados, através da observação de seu impacto nos participantes. A análise quantitativa foi realizada por Olsen e a qualitativa por Cabral.

O formato do questionário foi escolhido por Cabral entre os vários descritos e comentados por Olsen. As questões se referem aos objetivos do projeto de pesquisa. A primeira questão lista os cinco objetivos priorizados no planejamento da montagem, e as seguintes focalizam cada um destes objetivos, listando para cada um, cinco categorias a serem ordenadas de 01 a 05 , sendo 01 a que causou maior impacto ou risco. Foram assim 06 questões referentes a impacto e 06 referentes a risco.

Os pressupostos estatísticos incluíram um teste sobre a validade dos dados, uma vez que estes se referiam a 05 cenas independentes entre si - pretendeu-se assim verificar se as variáveis apontadas pelos atores destas distintas cenas poderiam ser consideradas como pertencentes à mesma população. Isto é, sendo as cenas independentes, as respostas obtidas poderiam ser relacionadas ao projeto como um todo, sendo assim representativas da estética teatral sob investigação?

O teste estatístico, teste de Friedman, se baseou na gradação de 01 a 05 dadas a cada questão. A validade é rejeitada se a probabilidade da ocorrência for menor ou igual a 0.005 . Validade aqui entendida como possibilidade dos dados serem generalizados para o universo investigado em sua totalidade.

As respostas dos 25 atores com formação em teatro foram examinadas independentemente das cenas a que pertenciam. No caso deste grupo, duas entre as seis questões sobre impacto, passaram no teste estatístico: "Que aspecto do teatro em trânsito o impressionou mais?" e "Em relação ao lugar, qual foi o maior impacto?" Olsen investigou estas duas questões mais detaIhadamente, isto é, considerando as variáveis incluídas em cada uma.

As respostas dos espectadores não precisaram passar pelo teste de Friedman, uma vez que estes responderam a partir das cinco cenas observadas; as respostas correspondem assim à recepção do espetáculo como um todo, e podem ser generalizadas à estética teatral sendo investigada.

Os gráficos abaixo exemplificam as opções dos atores referentes às variáveis que causaram maior impacto nos atores: dramaturgia, lugar, personagens, relação música - texto ou conteúdo sócio - histórico. Os números listados verticalmente correspondem à contagem das opções, e no sentido 
horizontal estão representadas, da esquerda para as direita a primeira, segunda, terceira, quarta e quinta opções.

\section{Gráfico 01}

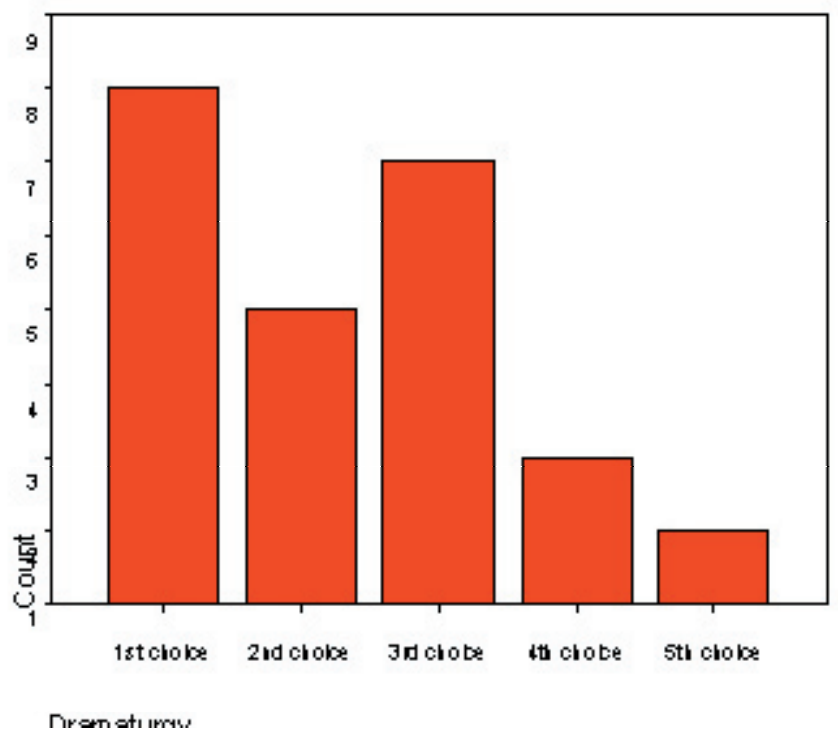

\section{Gráfico 02}

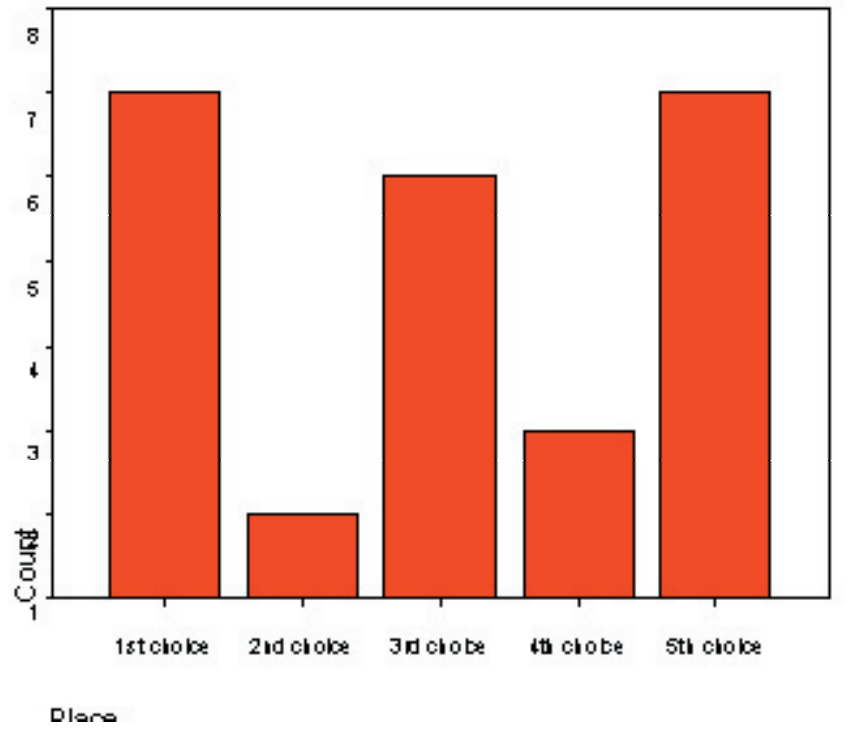




\section{Gráfico 03}

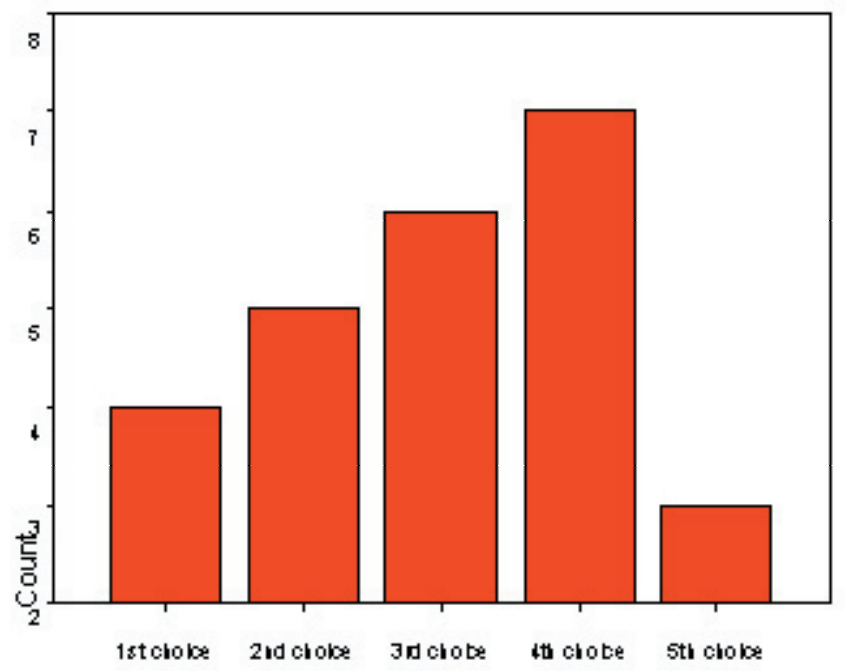

rhererters

\section{Gráfico 04}

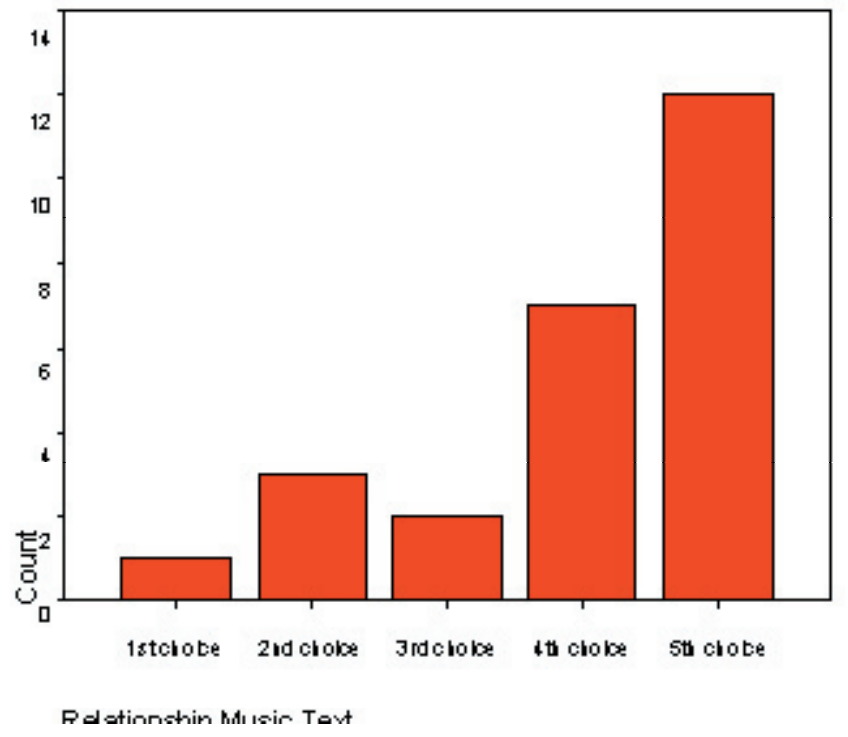




\section{Gráfico 05}

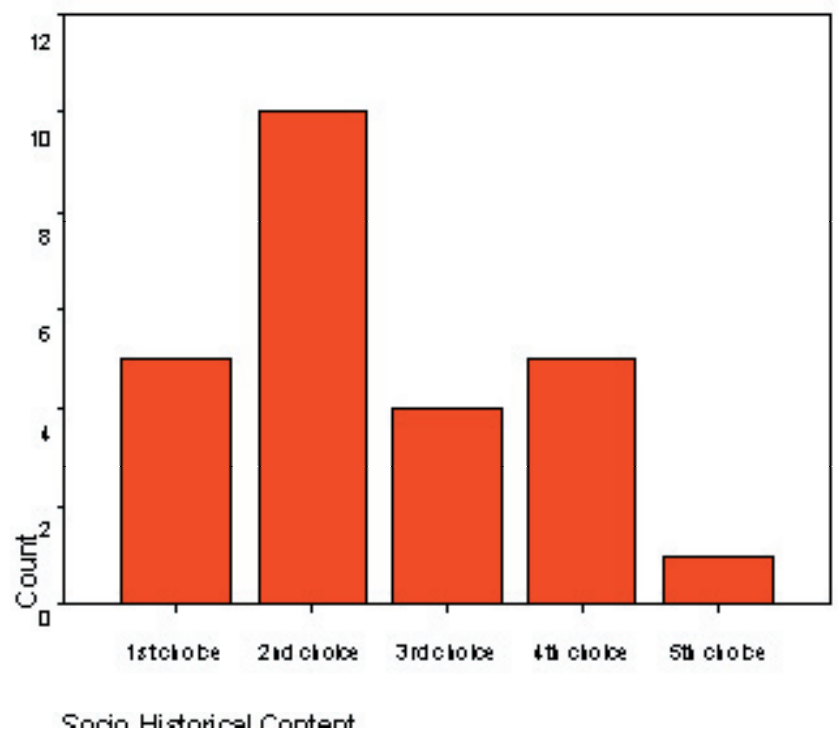

\section{Comentário sobre a Investigação Estatística}

É interessante notar que os estudantes de teatro, atores de cenas distintas, concordaram quanto ao aspecto que causou mais impacto nesta montagem.

Dramaturgia, segundo eles, foi o aspecto mais importante da cena, seguido por conteúdo histórico-social (segunda opção), lugar (terceira opção) e personagem (quarta opção). O menor impacto foi causado pela relação música-texto.

Em relação à dramaturgia, este grupo considerou situações inesperadas como a característica mais importante da narrativa, e em segundo lugar, os diálogos. Quanto ao conteúdo histórico-social fatos históricos pouco conhecidos foi a primeira opção, seguida pela história não-oficial e pela ressonância com a época atual, ambas opções empatadas em segundo lugar.

Outro aspecto no qual houve concordância por parte dos atores foi nas categorias beleza natural e lugares históricos, considerados como os mais importantes em relação ao uso do espaço.

O mesmo questionário foi respondido pelo mesmo número de espectadores, representantes de extratos sociais distintos da comunidade. As respostas foram similares àquelas dadas pelos atores, embora os espectadores não estivessem restritos a uma cena em particular - eles responderam sobre o trânsito como um todo, sem diferenciar as cinco cenas. 
Segundo o ponto de vista dos espectadores, o maior impacto foi causado por Dramaturgia, sendo que nesta categoria apontaram como primeira opção a variável possibilidade de interpretações distintas, e como segunda opção situações inesperadas.

A segunda categoria eleita pelos espectadores foi Lugar, e nesta variável a primeira opção foi dimensão histórica, seguida por recursos cênicos.

\section{Anotações em direção a uma análise qualitativa}

A decisão de realizar uma investigação quantitativa sobre a recepção dos participantes no tocante ao seu envolvimento em um projeto de teatro em comunidade decorreu principalmente do entendimento de que ter estes números à mão poderia ser um ponto de partida significativo para a realização de entrevistas e de uma análise qualitativa.

Em primeiro lugar, o questionário representa um instrumento eficaz para envolver todos os participantes na análise da experiência. Ele está estruturado a partir da estética particular a esta abordagem de teatro na comunidade, e ressalta as diferenças referentes à maneira pela qual os indivíduos percebem os elementos centrais do drama.

$\mathrm{Na}$ análise em processo estão sendo considerados os dados coletados com os atores com formação em teatro em contraponto com os dados dos espectadores. Dois aspectos ressaltam como ponto de partida:

Por um lado, fica visível que as alternativas com as quais ambos os grupos concordaram foram aquelas que resultaram de um trabalho intenso e mais aprofundado pelo grupo de pesquisa - a seleção de fatos históricos que tivessem ressonância com a época atual e seu cruzamento com histórias pessoais e comunitárias, obtidas através de entrevistas, foram tarefas que demandaram mais horas de trabalho e discussões em todas as experiências realizadas. O reconhecimento que estes procedimentos não foram suficientes para dar voz a um grupo grande e heterogêneo, exigiu mais do que um simples roteiro - foi necessário a presença de um dramaturgista para cada cena, o qual desenvolveu o roteiro após os primeiros ensaios e submeteu o texto ao grupo de pesquisa para revisão e sugestões de re-formatação.

Por outro lado, as diferentes recepções da mesma cena em muitos casos estiveram relacionadas com a especialização ou habilidade do receptor no que concerne o aspecto observado. Por exemplo, uma professora de dança, ao ser entrevistada, reconheceu que as dificuldades para criar coreografias com movimentos expressivos por crianças na faixa dos 7 anos de 
idade, durante um período de tempo tão curto quanto o disponível para esta montagem, a fez valorizar este tipo de trabalho mais do que qualquer outro. Outro exemplo foi dado pelos diretores das várias cenas - este reconheceram, também em entrevista, que suas avaliações estavam relacionadas com suas expectativas a respeito do trabalho; eles avaliaram seus atores de acordo com as intenções estabelecidas na etapa do planejamento.

Em segundo lugar, o questionário inclui a dimensão pedagógica de explicitar aos participantes a estrutura e os objetivos do projeto. A primeira etapa da pesquisa quantitativa se referiu à aplicação dos questionários aos alunos e professores de teatro que participaram da montagem como atores e diretores de cena. Seus testemunhos, em geral, foram de que se surpreenderam com a diversidade dos objetivos, embora em momentos distintos do processo de montagem tivessem tido consciência de todos eles. O fato é que o questionário permitiu a visualização do projeto de forma integral, o que facilitou a percepção das interações entre objetivos, cenas, e suas implicações na configuração da estética sendo investigada.

A segunda etapa da aplicação dos questionários envolveu os atores, com formação em teatro, entrevistando os atores da comunidade - cada ator aplicou o questionário, como base para a entrevista, com um dos atores da comunidade. Ter passado pela experiência, e aplicar o questionário sob a forma de entrevista, foi importante e necessário devido aos conceitos e estratégias mencionadas nas questões. Muito do fazer teatral, ao não ser formulado adequadamente no momento em que é proposto, é difícil de ser identificado de forma teórica.

A terceira parte da entrevista envolveu atores e equipe de pesquisa na entrevista com os espectadores. O processo de análise, até este momento, tem se concentrado na recepção dos atores versus a recepção dos espectadores.

Em terceiro lugar, ficou visível a contribuição deste tipo de pesquisa quantitativa para um olhar distanciado do pesquisador em relação ao objeto pesquisado. Neste caso, em particular, os resultados obtidos foram contrários às expectativas criadas pelo grupo de pesquisa, e isto favoreceu um novo olhar sobre a cena e o projeto.

A expectativa inicial de que haveria uma distinção significativa entre a recepção por parte dos alunos de teatro e por parte dos espectadores não se concretizou, e, em alguma medida, revelou-se no sentido oposto ao esperado.

O projeto tem focalizado a encenação de rituais e a interação canto - di- 
álogos, como forma de dar voz a todos os participantes. Outro aspecto enfatizado é a presença do contador de histórias em cena, como forma de introduzir ou mediar os conflitos e as informações históricas. Este(a) contador(a) é geralmente uma personagem da história recente da comunidade, que possa ser reconhecida como tal. A expectativa era que rituais, canto e personagens típicas da localidade obtivessem a preferência do público. Entretanto, a primeira opção do público foi Dramaturgia, e na segunda, Lugar, a primeira variável foi Dimensão Histórica.

É interessante notar que todas as cenas incluíram interações canto/música/dança-texto. Uma possível explicação para ser esta a última opção, por atores e espectadores, pode estar no fato de que foram os próprios elencos quem identificaram a música e definiram a forma como esta foi inserida na cena. Isto indica que não houve um desafio maior em termos de descoberta ou atuação. Além disso, a música selecionada era em grande parte, conhecida da comunidade, enquanto a estética teatral do trânsito foi nova para os observadores. Isto explica porque os únicos votos para música e canto foram dados pelos atores que trabalharam em uma cena onde 21 crianças, entre 07 e 09 anos, cantaram e dançaram músicas indígenas, em Guarani (língua dos índios que lá habitaram).

O fato de que as questões referentes a Risco não foram validadas pelo teste de Feldman não significa que este não ocorreu, de forma diferenciada, em cada cena. O que se pode observar com clareza é que o risco é específico a cada situação e não há como obter consenso em um trabalho caracterizado pela montagem de cenas independentes e distintas, em locais também distintos. O risco está assim relacionado diretamente com o conteúdo da cena (cruzamento das interfaces do texto teatral). Por exemplo, o risco de apresentar um conflito político da comunidade difere do risco de envolver crianças com técnicas circenses. Este entendimento aponta para o fato de que o questionário não pode ser visto como um meio para observar prioridades ou definir problemas, mas sim como um guia para perceber que com que tipo de risco cada grupo interagiu, e para mediar a entrevista.

Finalmente, esta análise da terceira experiência com o teatro em trânsito ainda não está concluída. São inúmeras as possibilidades de cruzamento dos dados - por exemplo, pode-se comparar a recepção dos atores de fora com a dos atores da comunidade; entre os atores das diferentes cenas; a recepção dos homens e das mulheres; de crianças e adultos, etc. Além disso, é possível comparar os resultados entre duas experiências, caso o questionário volte a ser aplicado. Para professores e estudantes este trabalho pode ser considerado enquanto prática como pesquisa. Diários de bordo e protocolos registram os processos interativos das montagens e fornecem material 
para o desenvolvimento de uma estética teatral de cunho intercultural para trabalhos em comunidades. A cada experiência novos elementos de impacto e fatores de risco são percebidos. O aspecto intercultural, além de favorecer uma perspectiva de estranhamento, no sentido de romper com as interações cotidianas, amplia também as possibilidades de leitura das cenas ao introduzir perspectivas distintas para interpretar ações e atitudes. O questionário, como subsídio para entrevistas, torna-se assim um instrumento importante na análise da recepção, permitindo entender como pessoas com formação e background cultural distintos percebem o espetáculo.

A análise da segunda experiência, realizada no município de Nova Trento/SC, transcorreu durante o processo de montagem, a partir de textos de Pierre Bourdieu $(1982,2001)$ e Henri Giroux $(1986,1997)$. No primeiro caso, foram focalizados os conceitos de habitus e violência simbólica. Procurou-se primeiramente detectar, na prática da própria equipe, posturas de produção e recepção incorporadas pelos diretores e atores a-criticamente, e suas implicações estéticas e pedagógicas. Paralelamente, discutiu-se a coordenação e atuação dos alunos e professores de teatro frente aos participantes da comunidade. Neste caso, o questionamento focalizou o conceito de violência simbólica, e a eventualidade de impor modelos ou juízos de valor.

Com textos de Giroux se fez o contraponto, procurando-se olhar a interação universidade-comunidade por outro ângulo: o potencial do teatro, um fazer artístico interativo e intercultural, para romper cruzar fronteiras e democratizar diferenças.

Neste sentido, a aplicação do questionário, na terceira experiência, foi uma tentativa de precisar melhor as diferentes perspectivas para aprofundar o debate teórico. No entanto, observou-se que estas diferenças não apareceram na apreciação do espetáculo; quando ocorreram, no processo de montagem, foram resolvidas em grupo. E, o acompanhamento do processo de montagem tornou evidente, a todos os participantes, que similaridades e diferenças, no tocante à produção e recepção do espetáculo, não estão distribuídas entre os com formação específica e os amadores, ou os "daqui" e os "de fora". Mas, para aprofundar esta questão será necessário um novo trânsito, com acompanhamento e documentação do processo de montagem e da recepção do produto final.

\section{Bibliografia}

BORDIEU, Pierre. O Poder Simbólico. 4a Edição. Rio de Janeiro, Bertrand Brasil, 2001. 

sil, 2001.

Meditações Pascalianas. Rio de Janeiro, Bertrand Bra-

BORDIEU, P. e PASSERON, J.C. A reprodução. Elementos para uma teoria do sistema de ensino. Rio de Janeiro, Francisco Alves, 1982.

BROOK, Peter. "The Culture of Links", in Pavis (1996:63-67).

CABRAL, Beatriz A V. "Plantas da Ilha - a História de Marina", in Arte em Foco (Florianópolis, DAC/UFSC, 1998), Vol. 1, No 1, pp: 77-94.

. (Org.) Ensino do Teatro - experiências interculturais. Florianópolis, DAC/UFSC, 1999.

"Rituals and Ethics - structuring participation in a theatrical mode", in Research in Drama Education (Inglaterra, Carfax Publishing Company, 2001), Vol. 6, No 1, pp 105-117.

"Impacto e Risco em Teatro na Escola e/ou Comunidade", in Memória ABRACE V, Salvador, UFBA, 2001.

"Teatro em Trânsito", in Memória ABRACE I - anais do I Congresso Brasileiro Pesquisa e Pós - Graduação em Artes Cênicas, pp 651-653, 1999.

. "A prática como Pesquisa na Formação do Professor", in Memória ABRACE VIII, Florianópolis, UDESC, 2003.

"Interconnected scenarios for ethical dialogues in drama", in Playing Betwixt and Between - the IDEA Dialogues 2001 (Eds B. Rasmussen e Anna-Lena Ostern). Bergen/Noruega, IDEA Publications, 2002.

COHEN, Renato. Work in Progress na Cena Contemporânea. São Paulo, Perspectiva, 1997.

1995.

. Performance como Linguagem. São Paulo, Perspectiva,

EPSKAMP, Kees P. Theatre in Search of Social Change - the relative significance of different theatrical approaches. Holanda, CESO, 1989.

ERVEN, Eugene van. Community Theatre - Global Perspectives. Londres, Routledge, 2001.

GIROUX, Henri. Teoria Crítica e Resistência em Educação. Petrópolis, Vozes, 1986.

. Os Professores como Intelectuais - rumo a uma pedagogia crítica da aprendizagem. Porto Alegre, Artes Médicas, 1997. KERSHAW, Baz. The Politics of Performance: Radical Theatre as Cultural Intervention. Londres, Routledge, 1992.

NEELANDS, Jonothan. Structuring Drama Work. Cambridge University Press, 1990. 
O'NEILL, Cecily. Drama Worlds. New Hampshire/USA, Heinemann, 1995.

PAVIS, Patrice.The Intercultural Performance Reader. London, Routledge, 1996.

Schechner, Richard. The Future of Ritual. New York, Routledge, 1993.

TURNER, Victor. From Ritual to Theatre. The human seriousness of play. New York, PAJ Publications, 1988. 